\section{Check for updates}

Cite this: Mater. Adv., 2021, 2, 3671

Received 10th March 2021, Accepted 12th April 2021

DOI: $10.1039 / \mathrm{d} 1 \mathrm{ma} 00210 \mathrm{~d}$

rsc.li/materials-advances

\title{
Rapid synthesis of diol homolog-based thermosets with tunable properties via ring-opening metathesis polymerization $\dagger$
}

\author{
Liuyang Zhang, Fei Huangfu, Wanrong Li and Po Yang (D) *
}

\begin{abstract}
This work aims to convert diols into thermosets with tunable properties. A series of diol-derived monomers have been synthesized and characterized. After mixing with second-generation Grubbs' catalyst, these liquid monomers polymerize completely in two minutes to form cross-linked structures, which benefits rapid manufacture of composites. These diol homolog-based thermosets have good thermal properties and mechanical properties, and their performance can be greatly enhanced by fabricating woven flax fiber composites. We believe these may help researchers design and explore novel promising sustainable diol-based polymers and materials with excellent properties.
\end{abstract}

\section{Introduction}

Thermosets, e.g., (for instance, phenolic resins, epoxy resins, and benzoxazines) have attracted extensive interest in scientific and industrial communities due to their fascinating properties like good thermal stability and chemical resistance. ${ }^{1-3}$ Nevertheless, some disadvantages such as brittleness and tedious polymerization process limit their application. Obviously, more thermosets with tunable properties are desirable and valuable.

On the other hand, bio-based polymers and materials have become increasingly popular. ${ }^{4-8}$ This is due to the intensified environmental awareness as well as the desire to substitute dwindling fossil resources with sustainable alternatives. ${ }^{9-12} \mathrm{~A}$ promising approach is to synthesize thermosets using sustainable or bio-based compounds (for instance, diols, isosorbide and furan) as feedstocks. ${ }^{13-15} \alpha, \omega$-Diols (diols, for instance, ethylene glycol, 1,3-propanediol, 1,4-butanediol and 1,5-pentanediol) can be obtained from biomass by microbial fermentation, hydrolysis and hydrogenolysis. ${ }^{16-18}$ As an abundant source of biomass compounds, diols are used as feedstock for the synthesis of bio-based thermosets, like polyurethanes and epoxy resins. ${ }^{19-21}$ Synthesis of these thermosets, nonetheless, requires a lot of energy, which produces lots of $\mathrm{CO}_{2}$ and $\mathrm{NO}_{x}$ due to the complex and tedious process. ${ }^{22}$ For example, diol-based epoxy resins need to be cured at $140{ }^{\circ} \mathrm{C}(1 \mathrm{~h})$ and $180{ }^{\circ} \mathrm{C}(1 \mathrm{~h}),{ }^{19}$ and polyurethane also takes several hours to cure. ${ }^{23,24}$ In addition, these thermosets in general do not perform well. ${ }^{25,26}$ Consequently, there is still

\footnotetext{
College of Polymer Science and Engineering, Sichuan University, State Key Laboratory of Polymer Materials Engineering, Chengdu, Sichuan 610065, China. E-mail: yangpo@scu.edu.cn

$\dagger$ Electronic supplementary information (ESI) available. See DOI: 10.1039/d1ma00210d
}

much interest in converting diols to thermosets with less energy, reducing their cost and environmental impact and furthering their application.

Ring-opening metathesis polymerization (ROMP) is a remarkable tool to rapidly convert cyclic olefins into acyclic dienes resulting in the formation of polymeric materials. ${ }^{27}$ Owing to ROMP, numerous polymers and polymeric materials like biomedical functional materials, ion exchange membranes, photoresist and photoinitiated polymers have been synthesized easily. ${ }^{28-34}$ With the aid of frontal polymerization technique, ROMP was also applied for rapid manufacture of high-performance cross-linked polymers and materials. ${ }^{35}$ If diols were converted to cyclic olefins moiety-containing monomers, they can be used to generate polymers via ROMP, which benefit to reduce the energy and expand their applications.

This work hence attempts to synthesize diol homolog-based thermosets and prepare composites via ROMP. Because the driving force of ROMP is the release of strain in the ring structures, norbornene-functionalized monomers can polymerize quickly in the presence of Grubbs' catalysts. ${ }^{36}$ For rapid synthesis of diol homolog-based thermosets, this contribution achieved a series of dinorbornenyl-diol-derived monomers from 5-norbornene-2carboxylic acid and diols, namely, ethylene glycol, 1,3-propanediol, 1,4-butanediol, 1,5-pentanediol, 1,6-hexanediol, 1,7-heptanediol, 1,8-octanediol, 1,9-nonanediol and 1,10-decanediol. Thorough investigation showed that these monomers can convert into cross-linked polymers in two minutes via ROMP. Moreover, the monomers, dinorbornenyl-pentanediol and dinorbornenyldecanediol based esters can also be applied to prepare composites rapidly using the vacuum-assisted resin-transfer mounding (VARTM) technique. According to the results, diol homologbased thermosets exhibit good properties and are fit for rapid 
fabrication of composites, and we developed new diol-based thermosets. Detailed analysis and discussions are provided below.

\section{Experimental}

\section{Materials}

5-Norbornene-2-carboxylic acid (98\%), ethylene glycol (99.5\%), 1,3-propanediol (98\%), 1,4-butanediol (99\%), 1,5-pentanediol (98\%), 1,6-hexanediol (98\%), 1,7-heptanediol (98\%), 1,8-octanediol (98\%), 1,9-nonanediol (98\%), 1,10-decanediol (98\%), triethylamine (99\%), oxalyl chloride (98\%), 4-dimethylaminopyridine (DMAP, 99\%), N-(3-dimethylamino-propyl)-N'-ethylcarbodiimide hydrochloride (EDCI, 97\%), methylene chloride (DCM, 99.5\%), $\mathrm{N}, \mathrm{N}$ dimethylformamide (DMF, 99.8\%), and methanol $(\mathrm{MeOH}$, 99.5\%) were purchased from Adamas-beta. Second-generation Grubbs' catalyst (GC2) was purchased from Sigma-Aldrich. Woven flax fiber was purchased from China Shaoxing linen manufacturer. Tributyl phosphite was purchased from Alfa Aesar. All the reagents were used as received.

\section{Synthesis of diol-based monomers}

Diol-based monomers were synthesized from 5-norbornene-2carboxylic acid and diols (i.e., ethylene glycol, 1,3-propanediol, 1,4-butanediol, 1,5-pentanediol, 1,6-hexanediol, 1,7-heptanediol, 1,8-octanediol, 1,9-nonanediol and 1,10-decanediol). Detailed syntheses are provided in the ESI. $\dagger$ The chemical structures of the monomers (NB2, NB3, NB4, NB5, NB6, NB7, NB8, NB9 and NB10) are listed in Fig. 1.

\section{Polymerization of diol-based thermosets}

Diol-based thermosets were synthesized from the corresponding monomers. The GC2 solution was freshly made as described previously in ref. 35 and then added to the monomers. After thoroughly mixing and rapidly transferring to the PTFE mold, the monomers were polymerized at $180{ }^{\circ} \mathrm{C}$ for 2 minutes.

\section{Preparation of composites}

This work used five sheets of dry woven flax fibers to prepare the composites through the vacuum-assisted resin-transfer moulding (VARTM) technique (Fig. S10, ESI $\dagger$ ). NB5 or NB10 was mixed with GC2/phosphite solution to obtain liquid resin as matrix for composites. A low vacuum $(-0.95 \mathrm{MPa})$ was applied to infuse the resins and compact the layup for producing the composites. After that, the layup was moved into an air oven at $180{ }^{\circ} \mathrm{C}$ for 2 minutes.

\section{Characterization}

Fourier transform infrared (FTIR) spectra were obtained from a Nicolet-560 spectrometer in the range of $4000-400 \mathrm{~cm}^{-1}$ at a resolution of $4 \mathrm{~cm}^{-1} \cdot{ }^{1} \mathrm{H}$ and ${ }^{13} \mathrm{C}$ NMR spectra were recorded on a Bruker TD-65536 NMR (400 MHz) spectrometer using $\mathrm{CDCl}_{3}$ as the solvent and tetramethylsilane as internal standard. Differential scanning calorimetry (DSC) tests were conducted using DSC Q20 (TA Instruments) at a heating rate of $10{ }^{\circ} \mathrm{C} \mathrm{min}{ }^{-1}$ under a constant nitrogen flow $\left(50 \mathrm{~mL} \mathrm{~min}^{-1}\right)$. Dynamic mechanical

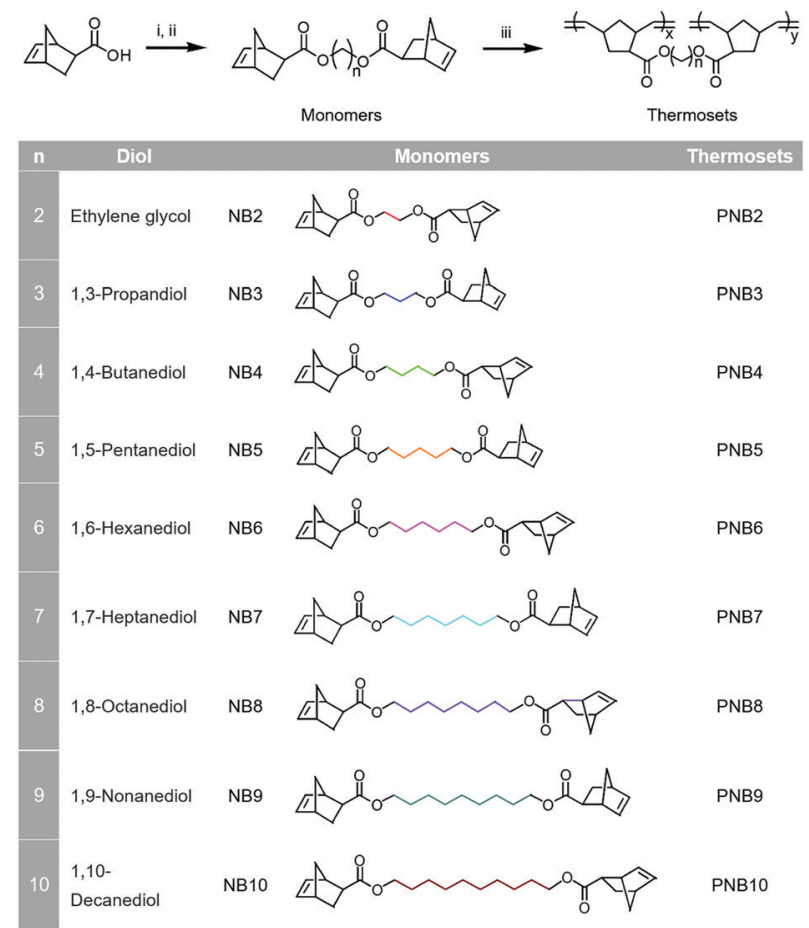

Fig. 1 Synthesis of diol-based monomers and thermosets. (i) oxalyl chloride, DCM. (ii) diols, triethylamine. (iii) GC2, $180^{\circ} \mathrm{C}, 2$ minutes.

analysis (DMA) measurements were performed using a TA Instrument DMA Q800 at $1 \mathrm{~Hz}$ in three-point bending mode. Specimens, $30 \mathrm{~mm} \times 10 \mathrm{~mm} \times 2 \mathrm{~mm}$ (length $\times$ width $\times$ thickness) were analyzed at a heating rate of $5{ }^{\circ} \mathrm{C} \min ^{-1}$ under nitrogen. Thermal gravimetric analysis (TGA) was performed with a TGA 4000 (PerkinElmer) system under nitrogen atmosphere from 40 to $500{ }^{\circ} \mathrm{C}$ at a heating rate of $10{ }^{\circ} \mathrm{C} \mathrm{min}^{-1}$. Tensile testing was conducted using an Instron 5967 with a $30 \mathrm{kN}$ load cell. The dog-bone specimens were tested following ISO standard 8256 type 1BB dimensions. Tests were performed at a crosshead speed of $2 \mathrm{~mm} \mathrm{~min}^{-1}$. We calculated the tensile modulus over a range of load from $2 \mathrm{~N}$ to $18 \mathrm{~N}$.

\section{Results and discussion}

All the diol-based thermosets were synthesized as shown Fig. 1, that is, the synthesis of diol-dinorbornenyl-derived monomers and polymerization of the corresponding monomers. All the monomers (i.e., NB2, NB3, NB4, NB5, NB6, NB7, NB8, NB9 and NB10) were synthesized from 5-norbornene-2-carboxylic acid and diols, and the detailed syntheses are given in the ESI. $\dagger$ After getting these monomers, this work focused on whether these monomers could be rapidly polymerized completely in the presence of GC2. We first used DSC to study the polymerization behaviour of the diol-derived monomers. After mixing with GC2 (50 ppm per norbornenyl double bond), the resins were probed by DSC, Fig. S1 (ESI $\dagger$ ).

As can be seen from the DSC curves, all the exothermic peaks were single peaks and appeared below $100{ }^{\circ} \mathrm{C}$. This indicated 
(a)

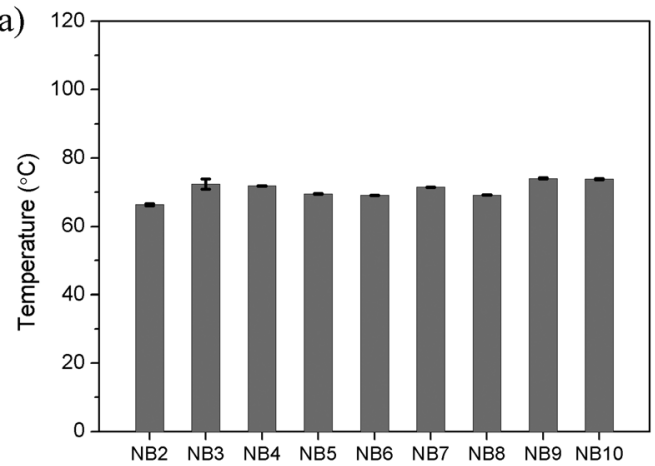

(b)

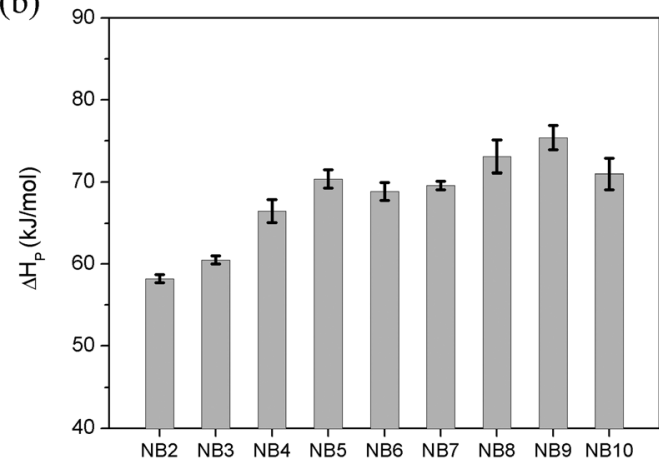

Fig. 2 (a) Peak temperatures, and (b) heat released from diol-derived monomers in the presence of GC2. Error bars are standard deviation, $N=3$.

that these monomers can polymerize at low temperature. The measured exothermic peak temperatures and the amount of heat released $\left(\Delta H_{\mathrm{P}}\right)$ were respectively plotted in Fig. 2(a) and (b). According to Fig. 2(a), a little variation was observed in the exothermic peak temperature, which was located at $\sim 72{ }^{\circ} \mathrm{C}$. For the amount of heat released, $\Delta H_{\mathrm{P}}$ increased as the alkyl chain length of the diols increased. For example, the $\Delta H_{\mathrm{P}} \mathrm{s}$ of NB2, NB5 and NB9 were respectively $58.2 \mathrm{~kJ} \mathrm{~mol}^{-1}, 70.4 \mathrm{~kJ} \mathrm{~mol}^{-1}$ and $75.4 \mathrm{~kJ} \mathrm{~mol}^{-1}$. However, the $\Delta H_{\mathrm{P}}$ of NB10 decreased compared to that of NB9. Steric structures affect the polymerization, since the driving force of ROMP is the release of strain in the ring structures. ${ }^{36}$ In this work, steric hindrance was present in the obtained monomers, namely, endo- and exo- diol-derived monomers. This is because there is a combination of isomers (endoand exo-) in the starting material, 5-norbornene-2 carboxylic acid. To understand the effect of steric hindrance on the polymerization, the ratios of endo- and exo- monomers were calculated by ${ }^{1} \mathrm{H}$ NMR spectroscopy and eqns S-1 and S-2. ${ }^{37}$ All the monomers exhibited a similar ratio of $\sim 70 / 30$, implying that steric hindrance had little influence on the polymerization. Diffusion and concentration of the monomers also affect polymerization, therefore, polymerization behaviors of the diol-based monomers varied as the flexible alkyl bridge structures of diols were altered. ${ }^{38-40}$

As mentioned previously, this contribution focused on rapid synthesis of diol-based thermosets, and we synthesized these thermosets at $180{ }^{\circ} \mathrm{C}$ for 2 minutes. The issue was whether the diol-derived monomers polymerized completely under the current process? This was investigated by detecting the heat released from the diol-based thermosets using DSC, and the curves are shown in Fig. S2 (ESI $\dagger$ ). As can be seen, no obvious exothermic peaks were observed, probably suggesting that the diol-derived monomers polymerize completely.

To better explore the polymerization, a control, methyl 5-norbornene-2-carboxylate (NB-Me) was synthesized, and its polymer, PNB-Me, was also synthesized at $180^{\circ} \mathrm{C}$ for 2 minutes. DSC (Fig. S3, ESI $\dagger$ ), FTIR (Fig. 3(a)), ${ }^{1} \mathrm{H}$ NMR (Fig. S4, ESI $\dagger$ ) and GPC (Fig. S5, ESI $\dagger$ ) confirmed that NB-Me polymerized completely. In the case of ${ }^{1} \mathrm{H}$ NMR spectrum, for example, cyclic double bond of NB-Me located at 5.92-6.18 $\mathrm{ppm}^{41,42}$ disappeared, and the resonances of acyclic double bonds appeared at $5.33 \mathrm{ppm}$ after polymerization. For FTIR, the bands corresponding to $=\mathrm{C}-\mathrm{H}$ stretching vibration (3142 and $3061 \mathrm{~cm}^{-1}$ ) and cyclic $\mathrm{C}=\mathrm{C}$ stretching vibration (1625 and $1571 \mathrm{~cm}^{-1}$ ) of NB-Me disappeared, and new band due to $=\mathrm{C}-\mathrm{H}$ out-of-plane rocking vibration was observed at $970 \mathrm{~cm}^{-1}$ in the spectrum of PNB-Me. ${ }^{43,44}$ With the aid of this control, polymerization behaviors of the diol-derived monomers were explored by FTIR spectroscopy (Fig. S6, ESI $\dagger$ ). For these monomers, the peaks located at $\sim 3128$ and $\sim 3060 \mathrm{~cm}^{-1}$ corresponding to $=\mathrm{C}-\mathrm{H}$ stretching vibration, and $\sim 1632$ and $\sim 1570 \mathrm{~cm}^{-1}$ assigned to cyclic $\mathrm{C}=\mathrm{C}$ stretching vibration disappeared after polymerization, while a new absorption by $=\mathrm{C}-\mathrm{H}$ out-of-plane rocking vibration was observed at $970 \mathrm{~cm}^{-1}$. In the case of NB2 (Fig. 3(b)), for instance, absorption at 3128 and $3061 \mathrm{~cm}^{-1}$ disappeared, while new bands appeared at $969 \mathrm{~cm}^{-1}$. This indicated that the diol-based monomers can convert into thermosets quickly under the current process. That is, this work rapidly synthesized diol-based thermosets,
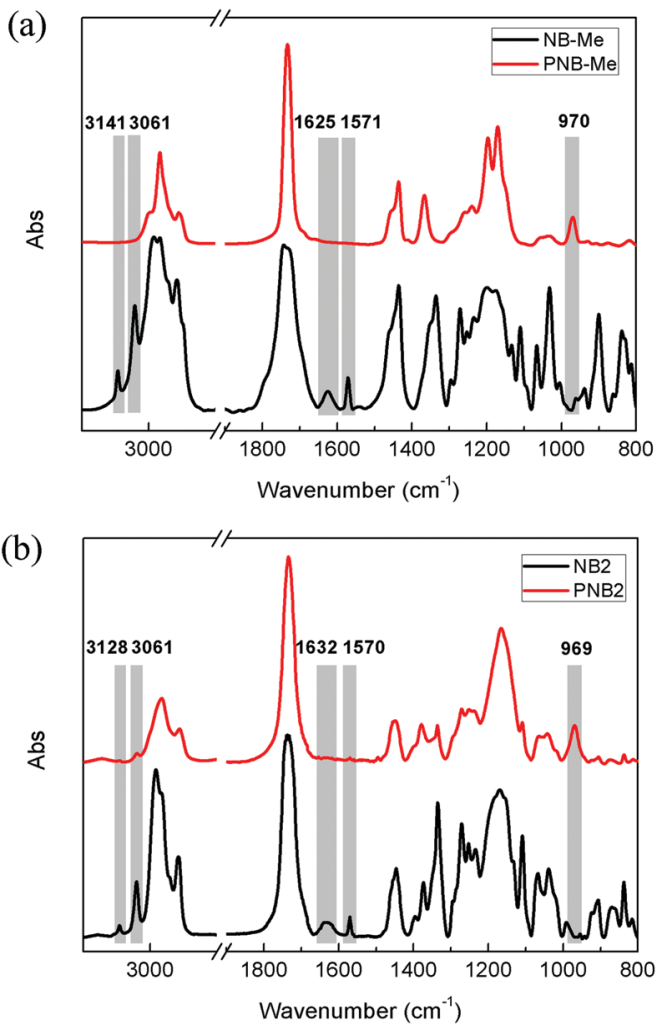

Fig. 3 FTIR spectra of (a) NB-Me and PNB-Me, and (b) NB2 and PNB2. 
Table 1 DMA data of diol-based thermosets

\begin{tabular}{lllll}
\hline & $\begin{array}{l}T_{\mathrm{g}}(\mathrm{Tan} \\
\left.\text { Delta, }{ }^{\circ} \mathrm{C}\right)\end{array}$ & $\begin{array}{l}E^{\prime}(298 \mathrm{~K}, \\
\mathrm{MPa})\end{array}$ & $\begin{array}{l}E^{\prime}\left(T_{\mathrm{g}}+40 \mathrm{~K},\right. \\
\mathrm{MPa})\end{array}$ & $\begin{array}{l}\rho\left(\times 10^{3},\right. \\
\left.\mathrm{mol} \mathrm{m}^{-3}\right)\end{array}$ \\
\hline PNB2 & 131 & 1649 & 147 & 13.2 \\
PNB3 & 132 & 1499 & 122 & 11.0 \\
PNB4 & 129 & 1255 & 115 & 10.4 \\
PNB5 & 130 & 1139 & 127 & 11.5 \\
PNB6 & 111 & 1101 & 102 & 9.6 \\
PNB7 & 103 & 717 & 47 & 4.3 \\
PNB8 & 106 & 976 & 68 & 6.5 \\
PNB9 & 112 & 942 & 82 & 3.7 \\
PNB10 & 102 & 686 & 40 & 3.8
\end{tabular}

and their crosslinked structures are shown in Fig. 1. Interestingly, it is difficult to probe the crosslinked polymers derived from ROMP of norbornene and its derivatives due to their complex architectures, like polydicyclopentadiene. This work may provide a method to explore the structures.

DMA was applied to evaluate the performance of the diolbased thermosets, Fig. S7 (ESI $\dagger$ ). The data gained from DMA were collected and listed in Table 1 . The $T_{\mathrm{g}}$ values of these thermosets exceeded $100{ }^{\circ} \mathrm{C}$. PNB2, PNB3, PNB4 and PNB5 had closer $T_{\mathrm{g}}$ values, and higher than those of PNB6, PNB7, PNB8, PNB9 and PNB10. This is probably caused by the crosslink density which plays an important role in the performance.

To prove the view, an equation from the statistical theory of rubbery elasticity was applied to estimate the crosslink densities. ${ }^{45,46}$ This equation can be expressed as

$$
\rho=E^{\prime} / 3 R T
$$

where $E^{\prime}$ is the storage modulus at $40 \mathrm{~K}$ above $T_{\mathrm{g}} . T$ is $T_{\mathrm{g}}+40 \mathrm{~K}$. $R$ is the universal gas constant, $8.314 \mathrm{~J} \mathrm{(mol} \mathrm{K})^{-1}$. The crosslink densities of diol-based thermosets were calculated and are shown in Table 1. As can be seen, the crosslink densities were roughly consistent with the variety of the $T_{\mathrm{g}}$ values. Crosslink densities of PNB2, PNB3, PNB4 and PNB5 were higher than those of PNB6, PNB7, PNB8, PNB9 and PNB10. These might be attributed to the alkyl bridge structures of diols.

In order to assess the mechanical properties of these diolbased thermosets, tensile properties were measured, Fig. S8 (ESI $\dagger$ ). The results are summarized and plotted in Fig. 4. As can be seen, all the thermosets' tensile strength exceeded $20 \mathrm{MPa}$, and PNB4 exhibited the best tensile strength (28.2 MPa). For tensile modulus, all these polymers were over $430 \mathrm{MPa}$, among which PNB3 had the best performance of $655 \mathrm{MPa}$. In addition, all these polymers showed elongation at break in the range of $7 \%-12 \%$, implying good toughness. This suggested that the diol-based thermosets have good mechanical properties.

Thermal stability of the diol-based thermosets was analyzed by thermogravimetric analysis (TGA). The TGA thermograms are shown in Fig. S9 (ESI $\dagger$ ), and the data obtained from TGA are listed in Table 2 . The $5 \%$ and $10 \%$ weight loss temperature exceeded 198 and $240{ }^{\circ} \mathrm{C}$, respectively, suggesting that these thermosets have good stability and can be widely applied.

Due to good mechanical properties, thermal stability and chemical resistance, thermosets are suitable to be used as the (a)

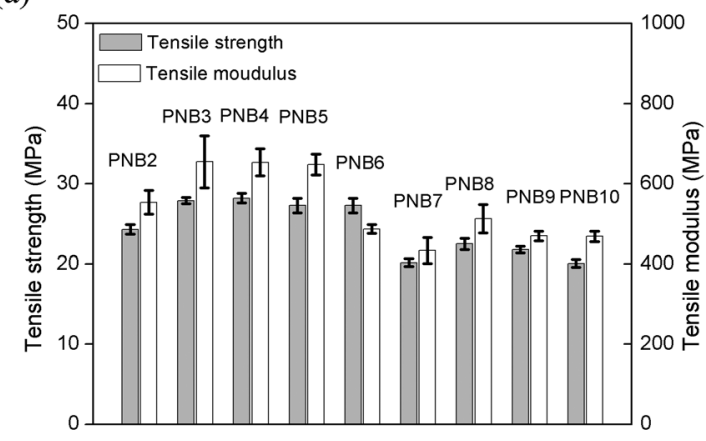

(b)

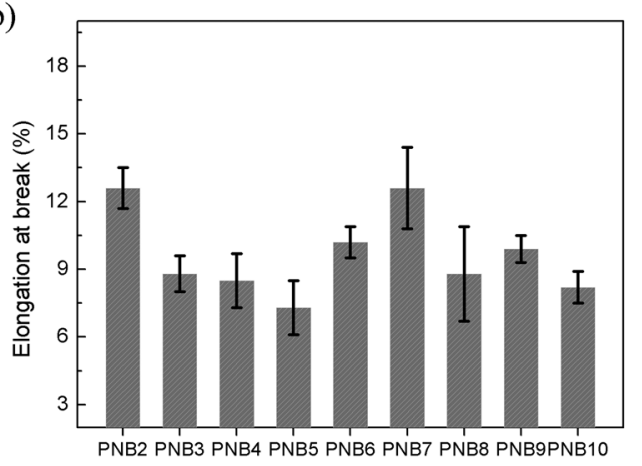

Fig. 4 (a) Tensile strength and tensile modulus, and (b) elongation at break of diol-based thermosets. Error bars are standard deviation, $N=5$.

Table 2 Summary of TGA data of diol-based thermosets

\begin{tabular}{llc}
\hline & $T_{\mathrm{d}} 5\left({ }^{\circ} \mathrm{C}\right)$ & $T_{\mathrm{d}} 10\left({ }^{\circ} \mathrm{C}\right)$ \\
\hline PNB2 & 198 & 240 \\
PNB3 & 217 & 240 \\
PNB4 & 240 & 333 \\
PNB5 & 254 & 385 \\
PNB6 & 259 & 389 \\
PNB7 & 249 & 380 \\
PNB8 & 310 & 394 \\
PNB9 & 259 & 385 \\
PNB10 & 249 & 366
\end{tabular}

matrix of composite components. Diol-derived thermosets can be a potential candidate for the matrix of composites; this work hence also attempted to fabricate the composites. In the case of traditional processing, the manufacture of thermoset components requires the monomer to be polymerized at $180{ }^{\circ} \mathrm{C}$ for several hours. ${ }^{47}$ However, following this work, one can fabricate composites in 2 minutes by polymerizing woven flax fibers infused with the monomer solution because diol-derived monomers can rapidly polymerize. PNB5/woven flax fiber (PNB5C) and PNB10/woven flax fiber (PNB10C) composites were manufactured through vacuumassisted resin transfer molding (VARTM), Fig. S10 (ESI $\dagger$ ).

Tensile properties of the composites were also measured, and the representative stress-strain curves are shown in Fig. 5. Tensile strength, tensile modulus and elongation at break of PNB5C were respectively 40.5 MPa, $927 \mathrm{MPa}$ and $16.7 \%$, and those of PNB10C were $35.3 \mathrm{MPa}, 536 \mathrm{MPa}$ and $24.4 \%$, respectively. Compared to PNB5 and PNB10 (Table 3), there were great enhancement in the tensile properties. This suggests that diol- 


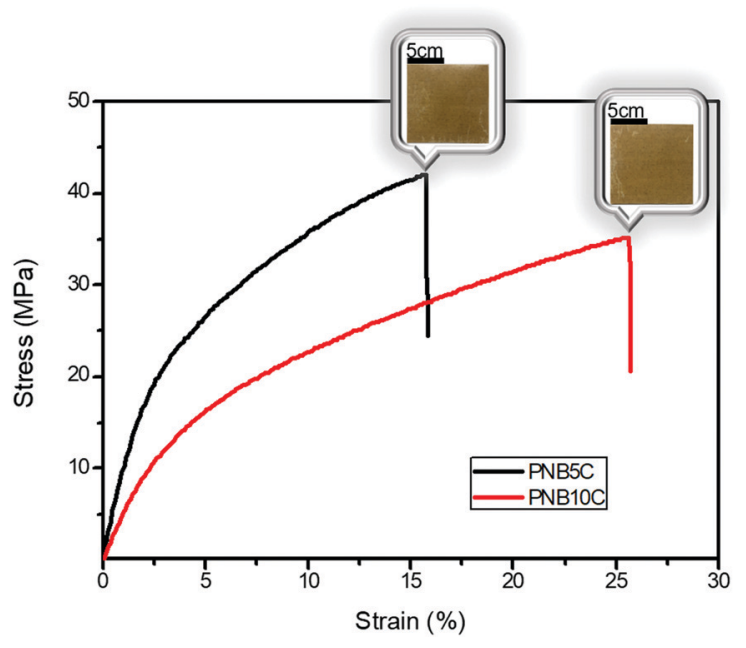

Fig. 5 Stress-strain curves of the composites.

Table 3 Tensile properties of the composites

PNB5 PNB5C PNB10 PNB10C

$\begin{array}{lllll}\text { Tensile strength }(\mathrm{MPa}) & 27.3 \pm 0.9 & 40.5 \pm 2.1 & 20.1 \pm 0.5 & 35.3 \pm 1.8\end{array}$ $\begin{array}{lllll}\text { Tensile module }(\mathrm{MPa}) & 648 \pm 26 & 927 \pm 60 & 469 \pm 13 & 536 \pm 43\end{array}$ Elongation at break (\%) $\quad 7.3 \pm 1.2 \quad 16.7 \pm 1.3 \quad 8.2 \pm 0.7 \quad 24.4 \pm 1.8$

based thermosets are good matrices for rapid manufacturing of composites.

\section{Conclusions}

In summary, this work focuses on rapid manufacturing of diolbased polymers and composites via ROMP. A series of diolderived monomers were synthesized. These liquid monomers can transform into thermosets at $180{ }^{\circ} \mathrm{C}$ in 2 minutes, which benefit the fabrication of composites rapidly through woven flax fibers infused with the monomer solution. Diol homologbased thermosets exhibited good thermal properties and mechanical properties, and their performance can be enhanced significantly by manufacturing woven flax fiber composites. We believe that diol-based thermosets can be widely used in various fields as a substitute for petroleum-based polymers.

\section{Conflicts of interest}

There are no conflicts to declare.

\section{Notes and references}

1 R. Duarah and N. Karak, RSC Adv., 2015, 5, 64456-64465.

2 Y. R. Xu, L. F. Guo, H. N. Zhang, H. M. Zhai and H. Ren, RSC Adv., 2020, 10, 22600.

3 P. Yang and Y. Gu, J. Polym. Res., 2011, 18, 1725-1733.

4 R. Hatti-Kaul, L. J. Nilsson, B. Z. Zhang, N. Rehnberg and S. Lundmark, Trends Biotechnol., 2020, 38, 50-67.

5 M. A. Hillmyer, Science, 2017, 358, 868-870.
6 D. K. Schneiderman and M. A. Hillmyer, Macromolecules, 2017, 50, 3733-3750.

7 Y. Q. Zhu, C. Romain and C. K. Williams, Nature, 2016, 540, 354-362.

8 N. Teramoto, Polymers, 2020, 12, DOI: 10.3390/polym12102386.

9 A. Gandini, Macromolecules, 2008, 41, 9491-9504.

10 A. L. Holmberg, K. H. Reno, R. P. Wool and T. H. Epps, Soft Matter, 2014, 10, 7405-7424.

11 R. Mulhaupt, Macromol. Chem. Phys., 2013, 214, 159-174.

12 K. J. Yao and C. B. Tang, Macromolecules, 2013, 46, 1689-1712.

13 S. Munoz-Guerra, C. Lavilla, C. Japu and A. M. de Ilarduya, Green Chem., 2014, 16, 1716-1739.

14 O. Nsengiyumva and S. A. Miller, Green Chem., 2019, 21, 973-978.

15 H. W. Park, M. Toan, H. J. Kim, J. H. Lee and S. Shin, J. Ind. Eng. Chem., 2020, 92, 184-190.

16 G. Q. Chen and M. K. Patel, Chem. Rev., 2012, 112, 2082-2099.

17 H. Yim, R. Haselbeck, W. Niu, C. Pujol-Baxley, A. Burgard, J. Boldt, J. Khandurina, J. D. Trawick, R. E. Osterhout, R. Stephen, J. Estadilla, S. Teisan, H. B. Schreyer, S. Andrae, T. H. Yang, S. Y. Lee, M. J. Burk and S. Van Dien, Nat. Chem. Biol., 2011, 7, 445-452.

18 J. Lu, L. B. Wu and B. G. Li, ACS Sustainable Chem. Eng., 2017, 5, 6159-6166.

19 D. Fourcade, B. S. Ritter, P. Walter, R. Schonfeld and R. Mulhaupt, Green Chem., 2013, 15, 910-918.

20 K. K. Tremblay-Parrado, C. Bordin, S. Nicholls, B. Heinrich, B. Donnio and L. Averous, Macromolecules, 2020, 53, 5869-5880.

21 H. Blattmann and R. Mulhaupt, Green Chem., 2016, 18, 2406-2415.

22 A. J. Timmis, A. Hodzic, L. Koh, M. Bonner, C. Soutis, A. W. Schafer and L. Dray, Int. J. Life Cycle Assess., 2015, 20, 233-243.

23 F. Zia, K. M. Zia, W. Aftab, S. Tabasum, Z. I. H. Nazli, M. Mohammadi and M. Zuber, Int. J. Biol. Macromol., 2020, 165, 1889-1899.

24 S. Naheed, M. Zuber, M. Barikani and M. Salman, Mater. Sci. Eng., B, 2021, 264, DOI: 10.1016/j.mseb.2020.114960.

25 A. Gallastegui, E. Gabirondo, F. Elizalde, N. Aranburu, D. Mecerreyes and H. Sardon, Eur. Polym. J., 2021, 143, DOI: 10.1016/j.eurpolymj.2020.110174.

26 J. M. Sadler, F. R. Toulan, G. R. Palmese and J. J. La Scala, J. Appl. Polym. Sci., 2015, 132, DOI: 10.1002/app.42315.

27 O. M. Ogba, N. C. Warner, D. J. O'Leary and R. H. Grubbs, Chem. Soc. Rev., 2018, 47, 4510-4544.

28 C. W. Bielawski and R. H. Grubbs, Prog. Polym. Sci., 2007, 32, 1-29.

29 A. E. Madkour, A. H. R. Koch, K. Lienkamp and G. N. Tew, Macromolecules, 2010, 43, 4557-4561.

30 J. A. Johnson, Y. Y. Lu, A. O. Burts, Y. Xia, A. C. Durrell, D. A. Tirrell and R. H. Grubbs, Macromolecules, 2010, 43, 10326-10335.

31 T. K. H. Trinh, G. Schrodj, S. Rigolet, J. Pinaud, P. LacroixDesmazes, L. Pichavant, V. Heroguez and A. Chemtob, RSC Adv., 2019, 9, 27789-27799. 
32 R. A. Weitekamp, H. A. Atwater and R. H. Grubbs, J. Am. Chem. Soc., 2013, 135, 16817-16820.

33 C. W. Cheng, X. H. He, S. M. Huang, F. Zhang, Y. Guo, Y. F. Wen, B. Wu and D. F. Chen, Int. J. Hydrogen Energy, 2020, 45, 19676-19690.

34 I. M. Rutenberg, O. A. Scherman, R. H. Grubbs, W. R. Jiang, E. Garfunkel and Z. Bao, J. Am. Chem. Soc., 2004, 126, 4062-4063.

35 I. D. Robertson, M. Yourdkhani, P. J. Centellas, J. E. Aw, D. G. Ivanoff, E. Goli, E. M. Lloyd, L. M. Dean, N. R. Sottos, P. H. Geubelle, J. S. Moore and S. R. White, Nature, 2018, 557, 223.

36 A. H. Hoveyda and A. R. Zhugralin, Nature, 2007, 450, 243-251.

37 J. M. Pollino, L. P. Stubbs and M. Weck, Macromolecules, 2003, 36, 2230-2234.

38 Y. Song, S. Zhang and P. Yang, Thermochim. Acta, 2018, 662, 55-63.

39 Y. Bai, P. Yang, S. Zhang, Y. Q. Li and Y. Gu, J. Therm. Anal. Calorim., 2015, 120, 1755-1764.
40 E. Skliutas, M. Lebedevaite, E. Kabouraki, T. Baldacchini, J. Ostrauskaite, M. Vamvakaki, M. Farsari, S. Juodkazis and M. Malinauskas, Nanophotonics, 2021, 10, 1211-1242.

41 C. H. Liu, L. D. Dugas, J. I. Bowman, T. Chidanguro, R. F. Storey and Y. C. Simon, Polym. Chem., 2020, 11, 292-297.

42 B. J. Sundell, J. A. Lawrence, D. J. Harrigan, S. B. Lin, T. P. Headrick, J. T. O’Brien, W. F. Penniman and N. Sandler, ACS Macro Lett., 2020, 9, 1363-1368.

43 T. J. Cuthbert, T. Li, A. W. H. Speed and J. E. Wulff, Macromolecules, 2018, 51, 2038-2047.

44 H. W. Thompson, D. L. Nicholson and L. N. Short, Discuss. Faraday Soc., 1950, 222-235.

45 H. Ishida and D. P. Sanders, J. Polym. Sci. Pol. Phys., 2000, 38, 3289-3301.

46 L. R. G. Treloar, The physics of rubber elasticity, Clarendon Press, Oxford, 2d ed., 1958.

47 D. Abliz, Y. G. Duan, L. Steuernagel, L. Xie, D. C. Li and G. Ziegmann, Polym. Polym. Compos., 2013, 21, 341-348. 